\title{
The importance of workforce surveillance, research evidence and political advocacy in the context of international migration of dentists
}
IN BRIEF
- Discusses inconsistencies in migrant dentist surveillance in major country- level governmental systems
- Argues that migration research must be invigorated.
- Suggests that global organisations, such as the FDI World Dental Federation, have an important role to play in advocating for improved dentist workfore surveillance.

\author{
M. Balasubramanian, ${ }^{* 1}$ D. S. Brennan, ${ }^{1}$ A. J. Spencer, ${ }^{1}$ K. Watkins ${ }^{2}$ \\ and S. D. Short ${ }^{3}$
}

\begin{abstract}
The international migration of dentists is an issue of pressing significance that poses several complex policy challenges. Policy-making is mainly constrained by the lack of workforce surveillance, research evidence and political advocacy - all three are required to work together, yet with different purposes. We first discuss the inconsistencies in migrant dentist surveillance in major country-level governmental systems (immigration departments, dentist registration authorities and workforce agencies). We argue that the limitations in surveillance collections affect independent research and in turn scholarly contributions to dental workforce policy. Differences in country-level surveillance collections also hinder valid cross-country comparisons on migrant dentist data, impeding global policy efforts. Due to these limitations, advocacy, or the political process to influence health policy, suffers, but is integral to future challenges on dentist migration. Countrylevel advocacy is best targeted at improving migrant dentist surveillance systems. Research interest can be invigorated through targeted funding allocations for migration research and by improving the availability of dentist surveillance data for research purposes. At the global level, the WHOs global code of practice for international recruitment of health personnel (a crucial advocacy tool) needs to be strengthened. Global organisations such as the FDI World Dental Federation have an important role to play in advocating for improved migrant dentist workforce surveillance and research evidence, especially in low- and middle-income countries.
\end{abstract}

'Global responsibility must be shared, because no country is an island in workforce development' Chen et al. ${ }^{1}$

In the contemporary era characterised by rapid globalisation, the international migration of health professionals, including dentists, is an issue of pressing significance that poses several policy challenges. ${ }^{2,3}$ Dentists migrate for a variety of reasons, and it is argued that the origins of the migration desire dwells deep into a migrant dentist's life-story. 'Source' countries lose their educational investment made in the migrating dentist, and are required to develop policies to reduce the shortage of dentists. ${ }^{3}$ The effect of brain drain can in theory be fatal, especially in low- and middle-income

\footnotetext{
${ }^{1}$ Australian Research Centre for Population Oral Health, School of Dentistry, University of Adelaide; ${ }^{2}$ Australian Dental Council, Melbourne; ${ }^{3}$ Head of the Discipline of Behavioural \& Social Sciences in Health, Faculty of Health Sciences, University of Sydney

*Correspondence to: M. Balasubramanian

Email:madhan.balasubramanian@adelaide.edu.au
}

\section{Refereed Paper}

Accepted 18 February 2015

DOI: 10.1038/sj.bdj.2015.195

${ }^{\circledR}$ British Dental Journal 2015; 218: 329-331 countries that rank considerably lower on several oral health indicators; ${ }^{4}$ however, it can be argued that migration contributes towards knowledge transfer or economic development in source countries (readers are advised to weigh both sides of the argument to understand the problem as a whole). ${ }^{5}$ 'Host' countries face an ethical dilemma of contributing to the brain drain, while simultaneously at the risk of restricting opportunities for locally-trained dentists, current dentists and potential dental students. ${ }^{6.7}$ The immigration of a dentist also does not guarantee employment; migrating dentists face social, cultural and professional hurdles before they are able to register and practise dentistry in a host country. ${ }^{8}$ Policies that address the concerns of both source and host countries, and migrant dentists themselves, require attention.

At the country level, effective policy making on any issue including dentist migration requires necessary data and evidence, but more importantly a 'political process' that stimulates interest on that issue. ${ }^{9}$ Dentist migration issues need to be considered with other issues on already crowded national agendas and should be aligned with the values and goals of public policy makers before it gains prominence as an issue of interest. Due to transnational flows of labour and knowledge, policy challenges regarding the international migration of dentists extend beyond the purview of a single country and often require a multilateral or global approach. ${ }^{1}$ The purpose of this opinion paper is to discuss the importance of three ingredients that we consider vital for policy-making on the international migration of dentists: workforce surveillance, research evidence and political advocacy. We offer arguments to make our case, both at the country and global levels.

\section{WORKFORCE SURVEILLANCE}

Surveillance involves the collection of migrant dentist workforce data by government organisations mainly for monitoring, planning and reporting purposes. Relevant organisations include immigration departments, dentist registration authorities and workforce agencies. Similar to the prevailing opinion on migrant physician and nursing workforce, ${ }^{2,10}$ we recognise incon- 
sistencies in the collection and reporting of migrant dentist data.

Immigration departments offer visas for migrant dentists and collect data on migrant dentist arrivals and departures. The nature of information collected by immigration officials might not necessarily reflect the currency of migrant dentists' occupation in respect to the new host country. Migrant dentists will need to successfully register as a dentist in order to seek employment. The assessment and examination of migrant dentists is necessary so the host country can ensure patient safety and maintain the appropriate standards of care. ${ }^{8}$ Registration authorities, such as dental boards, collect information on dentist qualifications and necessary pre-requisites follow before registration (that is, assessment and/or qualifying examinations). Registration data are usually minimal. Further monitoring of the migrant dentist workforce by relevant workforce agencies (based in government health departments) is necessary to understand migrant dentist characteristics (such as demographic characteristics and geographic distribution), also assisting in modelling the supply and demand of the dental workforce. National workforce agencies that specifically collect and report data on the dentist workforce are only common in the high-income countries. The poorer countries are at a disadvantage. Certainly the failure to monitor the emigration of the dentists contributes to brain drain.

An additional concern at all levels (that is, immigration departments, registration authorities and workforce agencies) of governmental data on migrant dentists is differences in information systems (mainly in collection and reporting of data) that exist from country to country. As a consequence, valid comparisons are hampered at a global level.

\section{RESEARCH EVIDENCE}

Research comprises 'creative work undertaken on a systematic basis in order to increase the stock of knowledge, including knowledge of man, culture and society: ${ }^{11}$ We consider that such evidence usually emerges from qualitative and/or quantitative work, conducted in independent research facilities.

Qualitative data on the reasons for migration and settling experiences in a new country give insight into migrant dentists' perceptions and attitudes. These data can be acquired by focus groups or in-depth interviews through a non-probabilistic sample and analysed using qualitative methods such as grounded theory, phenomenological techniques and so on. Even though such data are used in wider health professional migration policies, only a handful of such qualitative studies on dentist migration exist to inform policy-making decisions. ${ }^{3,8,12}$

Quantitative data can include primary research through surveys on migrant dentists, as well as secondary analysis of workforce surveillance data collections. Surveying research can assist us in better understanding the dimension, direction and determinants of dentist migration. It can also involve key issues such as job satisfaction and practice activity patterns in the host country. Policymaking decisions also require necessary data to ensure that the migration of overseas dentists does not constrain opportunities for locally-trained dentists and dental students in the host country. ${ }^{6,7}$ Scholarly evidence based on migrant dentist surveys is sparse and we believe that research interest on this has been minimal. Surveys also depend on the availability and quality of data from government organisations, which may have hindered meaningful research activity in many countries. In addition, future research will need to address the consequences of dentist migration, especially questions that address loss in education investment to source countries, health system effects due to loss of migrating dentists, and economic development due to remittances and knowledge transfer.

\section{POLITICAL ADVOCACY}

Advocacy is a political process that can stimulate, develop and inform policy. ${ }^{13}$ We believe advocacy becomes vital due to the nascent nature of workforce surveillance and migration research in many low- and middle-income countries. Advocacy is necessary to facilitate the translation of research evidence into policy, as well as to stimulate research interest, and research activity in the migration of dentists. Advocacy can also extend to improve migrant workforce surveillance.

At a country level, advocacy should be focused towards improving the quality of datasets that collect information on dentist migration. Dental associations, research groups and thought leaders involved in dentist migration or dental workforce research are key lobbyists best positioned to influence policy decisions of national governments. An integrated system for collecting dental workforce data that includes migration data, in addition to key issues such as motivations, job satisfaction, practice patterns and internal movement is important for dental workforce planning. ${ }^{2}$ This is a slow, stepwise process that requires considerable political thought and will. As a starting point, improved funding for dentist migration, and more generally dental workforce research, can encourage research groups, especially in low- and middle-income countries, to undertake such work.

At the global level, advocacy efforts should be focused on improving the comparability of dentist migration data, strengthening collaboration between state (national governments) and non-state players (dental associations, research groups and thought leaders), and possibly in developing a nodal agency for dentist migration issues. The WHO global code for international recruitment for health personnel (the code) is a crucial global advocacy tool. ${ }^{14}$ The code is considered as a core component of bilateral, national, regional and global responses to the challenges of health personnel migration and health systems strengthening. ${ }^{14}$ Recent reports on the monitoring and implementing of the code points towards the designation of a national authority for information exchange on health personnel migration (a minimum dataset approach involving collection and reporting of key health professional characteristics). ${ }^{2,15}$ While the report concludes that more efforts are required to strengthen implementation of the code, it has also called for greater collaboration among state and non-state players to raise awareness and reinforce the relevance of the code as a potent framework for policy dialogue on ways to address health personnel migration. ${ }^{15}$ This is particularly relevant in a privately-driven dental profession (where the majority of dental practitioners work in private practices). Therefore, organisations such as the FDI World Dental Federation fulfil an important advocacy function to raise awareness and influence policy decisions. ${ }^{16,17}$ The FDI is a federation of national dental associations, representing over a million dentists worldwide and is suitably placed to lead future efforts. Further research on the role of FDI on dentist migration advocacy is recommended.

\section{ON REFLECTION}

The multilateral nature of the dentist migration problem introduces complex policy challenges in different country contexts. The poor quality and lack of comparability of dentist migration data has hampered global policy efforts. While we understand that effective policy-making requires research evidence, we also argue that political advocacy is vital. The three factors for effective policy-making (workforce surveillance, research evidence and political advocacy) can be used to steer migration to make it less challenging for some countries and more beneficial for others. Global organisations such as the FDI have an important role to play in advocating for improved migrant 
dentist workforce surveillance and research evidence, especially in low- and middleincome countries.

The first author acknowledges the National Health and Medical Research Council (NHMRC) Centre for Research Excellence in Dental Health Services Research (1031310) Supporting Scholarship during the time this article was written.

The contents are solely the responsibility of the administering institution and authors, and do not reflect the views of NHMRC.

1. Chen L, Evans T, Anand S et al. Human resources for health: overcoming the crisis. Lancet 2004; 364: 1984-1990.

2. Buchan J, Sochalski J. The migration of nurses: trends and policies. Bull World Health Organ 2004; 82: 587-594

3. Balasubramanian M, Brennan D S, Spencer A J, Short S D. The 'global interconnectedness' of dentist migration: a qualitative study of the life-stories of international dental graduates in Australia. Heal Policy Plan 2014 [Epub ahead of print].

4. World Health Organisation. Working together for health: the world health report 2006. World Health Organisation 2006: 97-117. Online information available at http://www.who.int/whr/2006/ whr06_en.pdf?ua=1 (accessed February 2015).

5. Clemens M. Do visas kill? Health effects of African health professional emigration. Centre for Global Development. 2007. Online information available at http://www.cgdev.org/files/13123 file_Clemens_Do_visas_kill_3_.pdf (accessed February 2015).

6. Balasubramanian M, Short S D. The Commonwealth as the custodian of dental migratory ethics: views of senior oral health leaders from India and Australia. Int Dent J 2011; 61: 281-286.

7. Balasubramanian M, Short S D. Is the concept of ethics misplaced in the migration of Indian trained dentists to Australia? The need for better international co-operation in dentistry. Indian J Dent Res 2011; 22: 866-868.

8. Balasubramanian M, Brennan D S, Spencer A J, Watkins K, Short S D. Overseas-qualified dentists' experiences and perceptions on the Australian Dental Council assessment and examination process: the importance of support structures. Aust Heal Rev 2014; 38: 412-419.

9. Short SD. Elective affinities: research and health policy development. In Gardner H (ed) pp 65-82 Health policy in Australia. Melbourne. Oxford: Oxford University Press, 1997.

10. Stilwell B, Diallo K, Zurn P, Vujicic M, Adams 0 , $\mathrm{Dal}$ Poz M. Migration of health-care workers from developing countries: strategic approaches to its management. Bull World Health Organ 2004; 82: 595-600.

11. Organisation for Economic Cooperation and Development. The measurement of scientific and technological activities, Frascati Manual. Paris. 1993.

12. Ayers K M S, Thomson W M, Al-Hassiny H, Rich A $M$, Newton J T. A qualitative investigation of the experiences of immigrant dentists working in New Zealand. NZ Dent J 2008; 104: 97-103.

13. Baum F. The new public health: an Australian perspective. Melbourne: Oxford University Press, 1998.

14. World Health Organization. WHO global code of practice on the international recruitment of health personnel. World Health Organization. 2010. Online information available at http://www.who.int/hrh/ migration/code/practice/en/ (accessed February 2015).

15. Siyam A, Zurn P, Christian 0 et al. Monitoring the implementation of the who global code of practice on the international recruitment of health personnel. Bull World Health Organ 2013; 91: 816-23.

16. Benzian H M, Nackstad C, Barnard J T. The role of the FDI World Dental Federation in global oral health. Bull World Health Organ 2005; 83: 719-20.

17. World Dental Federation. FDI policy statement: ethical international recruitment of oral health professionals. 2006. Online information available at http://www.fdiworldental.org/media/11231/ Ethical-international-recruitment-of-oral-healthprofessionals-2006.pdf (accessed February 2015). 